\title{
Sabatier Reactor System Integration with Microwave Plasma Methane Pyrolysis Post-Processor for Closed-Loop Hydrogen Recovery
}

\author{
Morgan B. Abney ${ }^{1}$ \\ NASA Marshall Space Flight Center, Huntsville, AL, 35812 \\ Lee A. Miller ${ }^{2}$ \\ ECLS Technologies, LLC., Huntsville, AL, 35802 \\ and \\ Tom Williams ${ }^{3}$ \\ Jacobs Engineering Group, Inc., Huntsville, AL 35812
}

\begin{abstract}
The Carbon Dioxide Reduction Assembly (CRA) designed and developed for the International Space Station (ISS) represents the state-of-the-art in carbon dioxide reduction (CDRe) technology. The CRA produces water and methane by reducing carbon dioxide with hydrogen via the Sabatier reaction. The water is recycled to the Oxygen Generation Assembly (OGA) and the methane is vented overboard resulting in a net loss of hydrogen. The proximity to earth and the relative ease of logistics resupply from earth allow for a semi-closed system on ISS. However, long-term manned space flight beyond low earth orbit (LEO) dictates a more thoroughly closed-loop system involving significantly higher recovery of hydrogen, and subsequent recovery of oxygen, to minimize costs associated with logistics resupply beyond LEO. The open-loop ISS system for CDRe can be made closed-loop for follow-on missions by further processing methane to recover hydrogen. For this purpose, a process technology has been developed that employs a microwave-generated plasma to reduce methane to hydrogen and acetylene resulting in $75 \%$ theoretical recovery of hydrogen. In 2009, a 1-man equivalent Plasma Pyrolysis Assembly (PPA) was delivered to the National Aeronautics and Space Administration (NASA) for technical evaluation. The PPA has been integrated with a Sabatier Development Unit (SDU). The integrated process configuration incorporates a sorbent bed to eliminate residual carbon dioxide and water vapor in the Sabatier methane product stream before it enters the PPA. This paper provides detailed information on the stand-alone and integrated performance of both the PPA and SDU. Additionally, the integrated test stand design and anticipated future work are discussed.
\end{abstract}

\section{Acronyms}

$\begin{array}{ll}\mathrm{CO}_{2} & =\text { Carbon Dioxide } \\ \mathrm{CRA} & =\text { Carbon Dioxide Reduction Assembly } \\ \mathrm{CDRe} & =\text { Carbon Dioxide Reduction } \\ \text { ECLSS } & =\text { Environmental Control and Life Support Systems } \\ \mathrm{H}_{2} & =\text { Hydrogen }\end{array}$

\footnotetext{
${ }^{1}$ Aerospace Engineer, Environmental Control and Life Support Systems Development Branch, Bldg 4755 Room 403-7, Huntsville, AL 35812.

${ }^{2}$ Test Engineer, Environmental Control and Life Support Systems Development Branch, Bldg 4755 Room 103A, Huntsville, AL 35812.

${ }^{3}$ Senior Engineer, Environmental Control and Life Support Systems Development Branch, Bldg 4755 Room 110C, Huntsville, AL 35812.
} 


$\begin{array}{ll}\text { ISS } & =\text { International Space Station } \\ \text { ITS } & =\text { Integrated Test Stand } \\ \text { LEO } & =\text { Low Earth Orbit } \\ \text { LSS } & =\text { Lunar Surface Systems } \\ \text { MSFC } & =\text { Marshall Space Flight Center } \\ \text { OGA } & =\text { Oxygen Generation Assembly } \\ \text { PPA } & =\text { Plasma Pyrolysis Assembly } \\ \text { QMS } & =\text { Quadrupole Mass Spectrometer } \\ \text { SLPM } & =\text { Standard Liters per Minute } \\ \text { SmLPM } & =\text { Standard Milliliters per Minute } \\ \text { SDU } & =\text { Sabatier Development Unit } \\ \text { VVS } & =\text { Venturi Vacuum System } \\ \text { W } & =\text { Watts }\end{array}$

\section{Introduction}

$\mathrm{T}$ HE Environmental Control and Life Support Systems (ECLSS) groups within NASA have been tasked with developing key life support technologies for long-term manned space missions. For the purpose of atmosphere revitalization, carbon dioxide reduction (CDRe) has been identified as a critical need for any number of potential missions. Previous CDRe development and system integrated testing led to the maturation of the Carbon Dioxide Reduction Assembly (CRA). ${ }^{1-3}$ A flight CRA was delivered to the International Space Station (ISS) in March 2010. The CRA recovers oxygen by reacting carbon dioxide $\left(\mathrm{CO}_{2}\right)$ and hydrogen $\left(\mathrm{H}_{2}\right)$ to form water and methane through the Sabatier reaction as shown in Equation 1.

$$
\mathrm{CO}_{2}+4 \mathrm{H}_{2} \rightarrow 2 \mathrm{H}_{2} \mathrm{O}+\mathrm{CH}_{4}
$$

Water is fed to the Oxygen Generation Assembly (OGA) where it is electrolyzed to oxygen and $\mathrm{H}_{2}$. The methane is vented from ISS as an unusable waste product resulting in a net loss of system hydrogen. On ISS, the loss of $\mathrm{H}_{2}$ is not critical due to resupply capabilities from earth. However, for future missions outside of low earth orbit (LEO), where resupply will be more difficult, recovery of $\mathrm{H}_{2}$ becomes essential.

Recent progress in $\mathrm{H}_{2}$ recovery technology has led to the development of a Plasma Pyrolysis Assembly (PPA) developed and supplied by UMPQUA Research Company. ${ }^{4}$ The PPA uses a microwave-generated plasma to recover hydrogen and acetylene from methane, resulting in a theoretical hydrogen recovery of $75 \%$ as shown in Equation 2.

$$
2 \mathrm{CH}_{4} \rightarrow \mathrm{C}_{2} \mathrm{H}_{2}+2 \mathrm{H}_{2}
$$

Due to the nature of methane pyrolysis, other products are also possible with this technology including solid carbon, ethylene, and ethane, among others. These products will theoretically result in $100 \%, 50 \%$, and $25 \% \mathrm{H}_{2}$ recovery as shown in Equations 3-5, respectively.

$$
\begin{aligned}
\mathrm{CH}_{4} & \rightarrow \mathrm{C}(s)+2 \mathrm{H}_{2} \\
2 \mathrm{CH}_{4} & \rightarrow \mathrm{C}_{2} \mathrm{H}_{4}+2 \mathrm{H}_{2} \\
2 \mathrm{CH}_{4} & \rightarrow \mathrm{C}_{2} \mathrm{H}_{6}+\mathrm{H}_{2}
\end{aligned}
$$

In testing completed previously, ${ }^{4}$ only pure methane was fed as a reactant to the system with hydrogen fed to maintain a plasma and for cleaning. The ratio of $\mathrm{H}_{2}$ to methane in the reactor was not explored as a potential factor in the production of acetylene or other products. Additionally, there have been no investigations of the effect of varying the $\mathrm{H}_{2}$ inlet locations. However, the reported high methane conversion and $\mathrm{H}_{2}$ recovery rates clearly justified further investigation of the PPA both as a stand-alone unit and as an integrated system with state-of-the-art Sabatier technology.

As stated previously, the Sabatier reaction converts $\mathrm{CO}_{2}$ and $\mathrm{H}_{2}$ to methane and water. The CRA Sabatier on ISS was designed by Hamilton Sundstrand (Windsor Locks, $\mathrm{CT}$ ) to operate with excess $\mathrm{CO}_{2}$. This allows the system to 
maximize water recovery despite an insufficient hydrogen supply. However, for missions outside of low earth orbit, a methane post-processor can be used in conjunction with the CRA to recover additional hydrogen. The CRA can then be operated with excess hydrogen resulting in more oxygen recovery. Additionally, if a methane pyrolysis post-processor is to be used with the CRA, it may prove advantageous to operate $\mathrm{H}_{2}$-rich to prevent oxygenated compounds (residual $\mathrm{CO}_{2}$ ) from affecting methane pyrolysis. Because of the intended operation of the CRA, minimal work has been reported for the performance of the SDU in $\mathrm{H}_{2}$-rich operation. ${ }^{5}$ Therefore, before an integrated test with the PPA could be completed, an investigation of the operational performance of the SDU was necessary for $\mathrm{H}_{2}$-rich conditions.

Three tests have been conducted for the purpose of continued development of the PPA: PPA Stand-Alone Testing to provide baseline performance data of the system, SDU Stand-Alone Testing to explore the effect of a $\mathrm{H}_{2}$ rich feed stream to the system, and SDU/PPA Integrated Testing to evaluate the performance of each unit in an integrated configuration, to explore the effect of an impure methane feed stream to the PPA, and to investigate the effect of $\mathrm{H}_{2}$ feed variations within the PPA reactor. This document describes the methods and results of this testing and the proposed plans for future work.

\section{Hardware Description}

Two pieces of hardware were used for this testing: the SDU and the PPA. Additionally, an Integrated Test Stand (ITS) was built for SDU/PPA Integrated Testing. The following provides a description of the hardware and the ITS.

\section{A. Sabatier Development Unit}

The SDU (Hamilton Sundstrand, Windsor Locks, CT), shown in Figure 1, has the capability to receive $\mathrm{CO}_{2}$ from a Carbon Dioxide Removal Assembly and $\mathrm{H}_{2}$ from an OGA. However, for the purpose of this testing, $\mathrm{CO}_{2}$ and $\mathrm{H}_{2}$ were fed from K-bottles. A nitrogen feed line is used by the SDU for purging. Feed gases enter the Sabatier reactor where the system temperature is monitored by thermocouples and controlled with a heater and cooling fans. Product gases exit the reactor and flow to a condensing heat exchanger where water is condensed for collection in a water separator. The remaining product gases exit the system and either vent outside the test facility for stand-alone testing, or flow to the ITS for integrated testing. Pressure transducers and thermocouples are located throughout the system to monitor operation. A sample port, located at the exit of the condensing heat exchanger, enables monitoring of reactor products. Safety warnings and automatic shut-downs are controlled by system software to minimize the impact of operator error.

\section{B. Plasma Pyrolysis Assembly}

The PPA, shown in Figure 2, is packaged for stand-alone operation. Ports on the rear of the system allow for connection to $\mathrm{H}_{2}$ and methane K-bottles (Airgas, Inc., Radnor, PA). A manual control panel enables the user to control power to the mass flow controllers, the microwave and the system vacuum pump. A laptop computer provides a system control interface allowing the user to set flow rates and read reactor pressures, coolant temperatures, etc. The PPA reactor accepts feed gases through a total of four mass flow controllers. One flow meter feeds the methane stream to the system. The remaining three flow meters control $\mathrm{H}_{2}$ to the system.

The PPA uses a $\mathrm{H}_{2}$ plasma for the pyrolysis of methane. Pure $\mathrm{H}_{2}$ is fed to the reactor through three ports: the main port, the microwave window sweep port, and the view sweep port. The main port supplies $\mathrm{H}_{2}$ to fuel the plasma. Both window sweep ports provide a sweep flow of $\mathrm{H}_{2}$ necessary to minimize carbon build-up on the microwave and view windows. The methane stream is fed to the reactor through four small ports, collectively called the "methane feed port." These ports surround the outlet port which is located directly opposite the main port. A pressure transducer located on the reactor monitors pressure and provides data for automatic safety shut-down in the event pressure rises above 70 Torr. Microwaves are applied to the reactor from the Microwave Generation and Transmission Subsystem. A carbon trap at the outlet of the reactor collects any solid carbon produced during the reaction. A Quadrupole Mass Spectrometer (QMS) (Stanford Research Systems, Sunnyvale, CA) provides gas constituent data at the methane inlet and the outlet of the system. System pressure is controlled via vacuum pump and a pressure regulator. All areas of the system at or above atmospheric pressure are contained within a hazardous gas isolation enclosure. The enclosure is monitored by a Combustible Gas Sensor which will alarm and shut the system down well before the Lower Explosion Limit (LEL) is reached. 


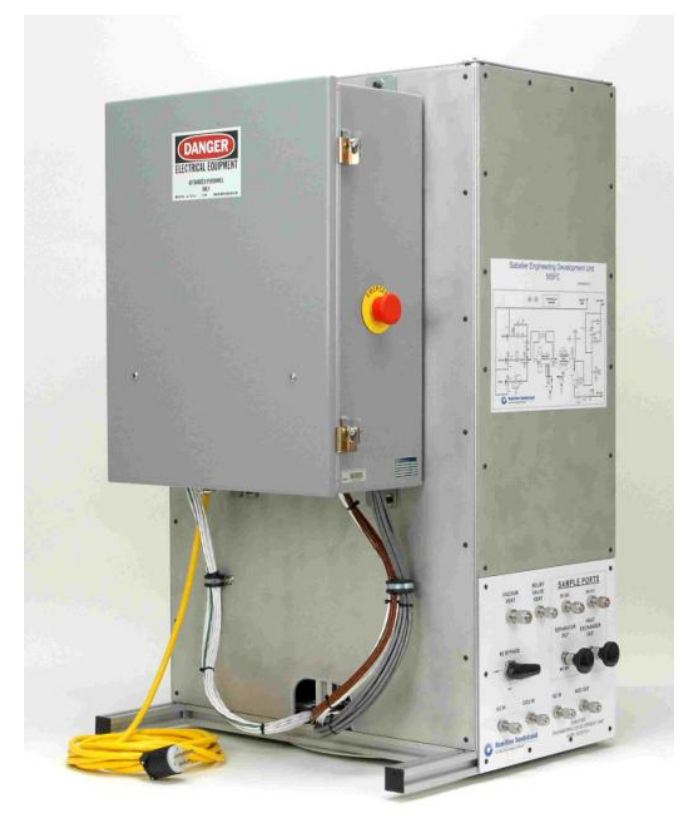

Figure 1. Sabatier Development Unit. The SDU was built as a development model for state-of-the-art CRA technology by Hamilton Sundstrand.

\section{Integrated Test Stand}

The ITS is the sum of components necessary to integrate the SDU and PPA hardware. A system schematic including the SDU and PPA is shown in Figure 3. The SDU and ITS are connected to a nitrogen purge and Venturi Vacuum System (VVS) providing a constant vacuum on the system to an outside vent. At the exit of the SDU, the methane product stream can be directed in one of two directions: to the VVS, or to the sorbent bed leading to the PPA. A pressure controller (PC516 in the schematic) can be set such that system pressures are maintained as flow rates through the SDU and PPA are independently controlled.

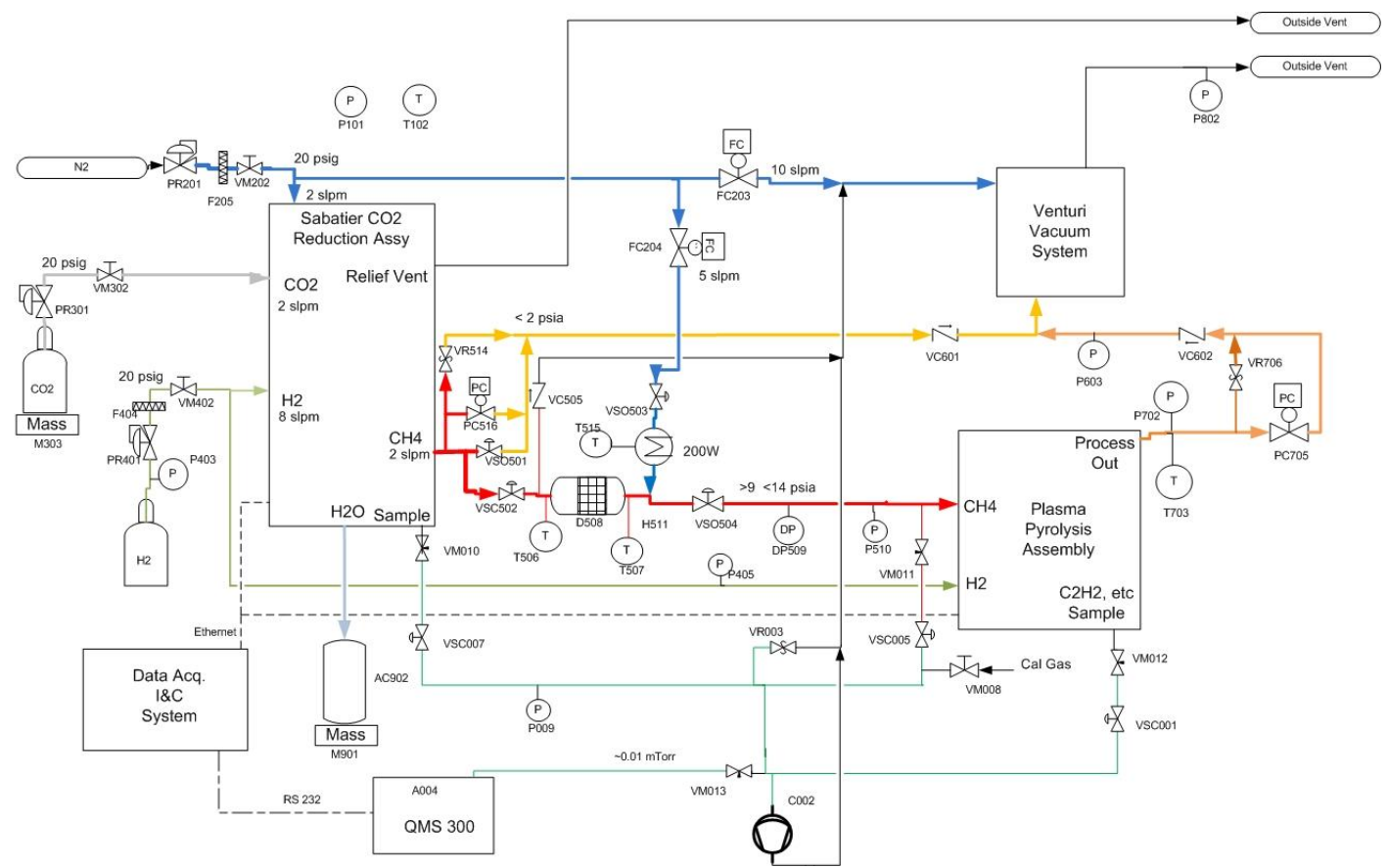

Figure 3. SDU/PPA Integrated Test Stand. The Integrated Test Stand contains the Sabatier Development Unit, the Plasma Pyrolysis Assembly, and all components necessary to complete integrated testing.

4

American Institute of Aeronautics and Astronautics 
The system sorbent bed, containing a total of $1058.9 \mathrm{~mL}$ of sorbent material including $264.7 \mathrm{~mL}$ of Sorbead $\mathrm{R}^{\mathrm{TM}}$ desiccant (Delta Adsorbents, Roselle, IL), 264.7mL of 13X zeolite (Grace Davison, Baltimore, MD) and 529.4mL of 5A zeolite (Grace Davison, Baltimore, MD), was over-sized to ensure maximum adsorption of residual water and $\mathrm{CO}_{2}$ in the methane product stream over the duration of a test series. A dew point sensor downstream of the sorbent bed monitors water content in the gas stream to ensure a dry feed to the PPA. For integrated testing, the QMS can sample from three locations in the system including the exit from the SDU, the entrance to the PPA, and the exit from the PPA. System temperatures and pressures are monitored by the integrated system software. Hazard controls are in place to automatically shutdown the system in the event of over-pressurization or excessive temperatures.

\section{Methods}

As mentioned previously, three tests were completed including PPA Stand-Alone Testing, SDU Stand-Alone Testing, and SDU/PPA Integrated Testing. The following information provides detailed testing objectives and methods.

\section{A. PPA Stand-Alone Testing}

The primary objective of PPA Stand-Alone Testing was to evaluate the baseline performance of the PPA. The system was given controlled set-points and operated as delivered. Note that during stand-alone testing, there was no individual control of $\mathrm{H}_{2}$ flow meters. A control algorithm was built into the system and allowed for manual control of total $\mathrm{H}_{2}$ flow to the reactor, but no control regarding the distribution of hydrogen to each flow meter individually. Total system flow rates were varied from 0.375 to 3.5 standard liters per minute (SLPM). In each run, a 4:1 ratio of $\mathrm{H}_{2}$ to methane was maintained. Microwave power was set at either 600 or 700 Watts (W). The reaction chamber was controlled to $\sim 48.3$ Torr. Each test point was repeated three times and trials were randomized to minimize error.

\section{B. SDU Stand-Alone Testing}

SDU Stand-Alone Testing was completed to evaluate the SDU performance under $\mathrm{H}_{2}$-rich conditions. The SDU $\mathrm{CO}_{2}$ feed rate was varied to correspond to either a crew of 2 or 4 . The ratio of $\mathrm{H}_{2}$ to $\mathrm{CO}_{2}$ was varied from 3 to 6 at intervals of 0.5 for 4 -crew feed rates and from 3.5 to 6 for 2-crew feed rates. Testing was randomized to minimize error and methane product stream composition was recorded for each test point.

\section{SDU/PPA Integrated Testing}

The objective of SDU/PPA Integrated Testing was to evaluate the performance of each piece of hardware in an integrated configuration. For Integrated Testing, the flow meters to the PPA were separated and could be controlled independently. In each test, total methane feed to the system was maintained at 200 SmLPM and microwave power was maintained at 700W. Testing was completed in four parts: SDU Performance Comparison, Method 1, Method 2, and Method 3.

\section{SDU Performance Comparison}

The SDU Performance Comparison was completed to evaluate the ongoing performance of the SDU. SDU product data was taken from the SDU Stand-Alone Test and compared to that from Methods 1-3 of the SDU/PPA Integrated Test.

\section{SDU/PPA Integrated Test: Method 1}

The purpose of Method 1 testing was to determine the effect of total system $\mathrm{H}_{2}$ on methane conversion and pyrolysis products. The SDU was operated with $\mathrm{CO}_{2}$ feed equivalent to a crew of $4 . \mathrm{H}_{2}$ was added to the SDU at ratios between 4 and 6 . External $\mathrm{H}_{2}$ was fed to the main port, the window sweep port, and the view sweep port at 450 SmLPM, 283 SmLPM, and 67 SmLPM, respectively (56\%, 35\%, and 9\% of external $\mathrm{H}_{2}$ feed, respectively). The total sum of external $\mathrm{H}_{2}$ feed was 800 SmLPM. This provided the minimum 4:1 $\mathrm{H}_{2}$ to methane ratio as controlled in PPA Stand-Alone Testing. Due to the addition of $\mathrm{H}_{2}$ as an impurity in the methane feed, the actual $\mathrm{H}_{2}$ to methane ratio during testing varied from 4.30 to 6.11. Each system set point was repeated once.

\section{SDU/PPA Integrated Test: Method 2}

The purpose of Method 2 testing was to determine the effect of varying the source of $\mathrm{H}_{2}$ while keeping the total system $\mathrm{H}_{2}$ constant. The $\mathrm{SDU}$ was operated with $\mathrm{CO}_{2}$ feed equivalent to a crew of $4 . \mathrm{H}_{2}$ was added to the SDU at 
ratios between 4 and 6 . External $\mathrm{H}_{2}$ was added to the main port, the window sweep port, and the view sweep port in different quantities for each trial, but always at $56 \%, 35 \%$, and $9 \%$ of the total external feed, respectively. Total $\mathrm{H}_{2}$ in the system was maintained at 800 SmLPM resulting in a 4:1 ratio of $\mathrm{H}_{2}$ to methane in the PPA reactor. Each system set point was repeated once.

\section{SDU/PPA Integrated Test: Method 3}

The purpose of Method 3 testing was to evaluate the effect of varying the ratios of the external $\mathrm{H}_{2}$ feeds (main port, window sweep port, and view port) with respect to each other and the $\mathrm{H}_{2}$ flowing into the reactor in the methane feed stream. Additionally, this test was designed to evaluate the effect of a broader range of total system $\mathrm{H}_{2}$ on the conversion of methane and the resulting products. The SDU was operated with a $\mathrm{CO}_{2}$ feed equivalent to a crew of 4. Four factors were identified for variation at three levels as shown in Table 1 . The ratio of $\mathrm{H}_{2}$ to $\mathrm{CO}_{2}$ in the SDU feed was set at 4, 4.5, or 6. The main port sweep was controlled to 50, 225 or 450 SmLPM. The window sweep flow was controlled to 140,280 , or 420 SmLPM. The view port sweep flow was controlled to 35,70 or 140 SmLPM. These controls resulted in total system $\mathrm{H}_{2}$ to methane ratios between 1.53 and 6.08. Additionally, varying the flow of external $\mathrm{H}_{2}$ to the system resulted in the $\mathrm{H}_{2}$ in the methane feed constituting between 7.3 and $47.1 \%$ of the total system $\mathrm{H}_{2}$. Note that due to time and monetary constraints, SDU ratios were not randomized. Randomization was completed for the PPA controls only. Additionally, no repeats were completed.

Table 1. SDU/PPA Integrated Test Method 3 Factors and Levels. Four factors at three levels each were chosen for Method 3 testing.

\begin{tabular}{|c|c|c|c|c|}
\hline \multirow{2}{*}{$\begin{array}{c}\text { Factor } \\
\text { Level }\end{array}$} & $\begin{array}{c}\text { SDU Feed } \\
\text { Ratio }\end{array}$ & $\begin{array}{c}\text { Main Port } \\
\text { Sweep } \\
\text { (SmLPM) }\end{array}$ & $\begin{array}{c}\text { Window } \\
\text { Sweep } \\
\text { (SmLPM) }\end{array}$ & $\begin{array}{c}\text { View Port } \\
\text { Sweep } \\
\text { (SmLPM) }\end{array}$ \\
\hline $\mathbf{1}$ & 4 & 50 & 140 & 35 \\
\hline $\mathbf{2}$ & 4.5 & 225 & 280 & 70 \\
\hline $\mathbf{3}$ & 6 & 450 & 420 & 140 \\
\hline
\end{tabular}

\section{Results and Discussion}

The results of PPA Stand-Alone Testing, the SDU Stand-Alone Test, and the SDU Performance Comparison and the three Methods of the SDU/PPA Integrated Test are detailed below.

\section{A. PPA Stand-Alone Testing}

PPA Stand-Alone Testing was completed to evaluate the baseline performance of the PPA. More specifically testing was intended to determine the effect of methane feed flow rate and microwave power on methane conversion and $\mathrm{H}_{2}$ recovery. A graph of methane feed flow rate versus methane conversion is shown in Figure 4. This graph indicates microwave power of $700 \mathrm{~W}$ results in significantly higher methane conversion than $600 \mathrm{~W}$ at all feed rates except the lowest feed rate tested (75 SmLPM), where there was no significant difference in the two power levels. Additionally, methane conversion is significantly better at flow rates between 75 and 200 SmLPM than flow rates greater than or equal to 400 SmLPM. Error bars, denoting standard deviation, show the consistent performance of the PPA between runs.

A graph of the methane feed rate versus $\mathrm{H}_{2}$ recovery is seen in Figure 5. This graph shows a similar trend to the methane conversion graph. $\mathrm{H}_{2}$ recovery is significantly better at $700 \mathrm{~W}$ than $600 \mathrm{~W}$ for all methane feed rates except the lowest two (75 and $100 \mathrm{SmLPM}$ ). Additionally, $\mathrm{H}_{2}$ recovery at methane flow rates between 75 and $200 \mathrm{SmLPM}$ is significant better than recovery at flow rates greater than or equal to 400 SmLPM.

For the purpose of technology development of long-term manned space flight, power and energy efficiency are very important. Energy efficiency $(\eta)$, as it applies to microwave plasmas, is determined by Equation 6 :

$$
\eta=\frac{\chi * \Delta H}{E_{v}}
$$


where $\chi$ is the conversion of methane, $\Delta \mathrm{H}$ is the enthalpy of formation of acetylene, and $\mathrm{E}_{\mathrm{v}}$ is the specific energy input per molecule in the system. ${ }^{6} \mathrm{E}_{\mathrm{v}}$ is calculated as shown in Equation 7:

$$
E_{v}=\frac{\text { Discharge Power }}{\text { Gas Flowrate }}
$$

Figure 6 provides a graphical view of approximate energy efficiency versus methane flow rate to the system during PPA Stand-Alone Testing. Energy efficiency was shown to improve with methane (and system) flow rate despite reduced methane conversion.

The PPA Stand-Alone Test showed that, at the methane flow rates tested, methane conversion and $\mathrm{H}_{2}$ recovery were better at the higher microwave power $(700 \mathrm{~W})$. Higher microwave power can be related directly to the level of ionization of the plasma in the reactor. Therefore, improved conversion of methane would be expected at the higher level. Lower methane feed rates $(\leq 200$ SmLPM) resulted in better methane conversion and $\mathrm{H}_{2}$ recovery as compared to the higher methane feed rates ( $\geq 400$ SmLPM). Overall, a maximum of $91 \%$ methane conversion and $68 \% \mathrm{H}_{2}$ recovery was achievable at the lowest flow rate. At the highest flow rates tested, methane conversion was $\sim 70 \%$ with $\mathrm{H}_{2}$ recovery at $\sim 50 \%$. As expected, lower flow rates result in a longer residence times leading to improved conversion. Finally, energy efficiency for the highest flow rate, where methane conversion was the lowest, neared $13 \%$, significantly lower than the theoretical maximum for our system of $63 \%$ as described by Fridman. ${ }^{6}$ However, at the lowest flow rates, where methane conversion was highest, energy efficiency was as low as $\sim 2 \%$. This data indicates substantial energy inefficiencies at all tested flow rates and provides significant potential for improvement to the system. However, development efforts should be directed toward higher flow rate systems to provide adequate reduction for long-term missions. At the higher flow rates, the energy efficiency was highest indicating that the energy was being more effectively utilized by the system. Improving methane conversions at these feed rates may require improved geometry within the system to maximize methane residence time, while maintaining energy efficiency, at the very least.

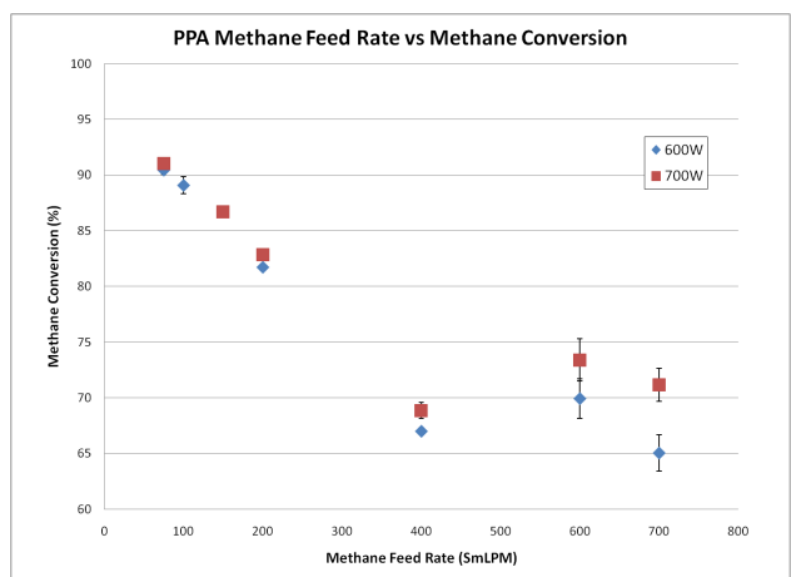

Figure 4. PPA Stand-Alone Methane Conversion. Methane conversion as a function of methane feed rate and microwave power. Error bars indicate standard deviation $(n=3)$.

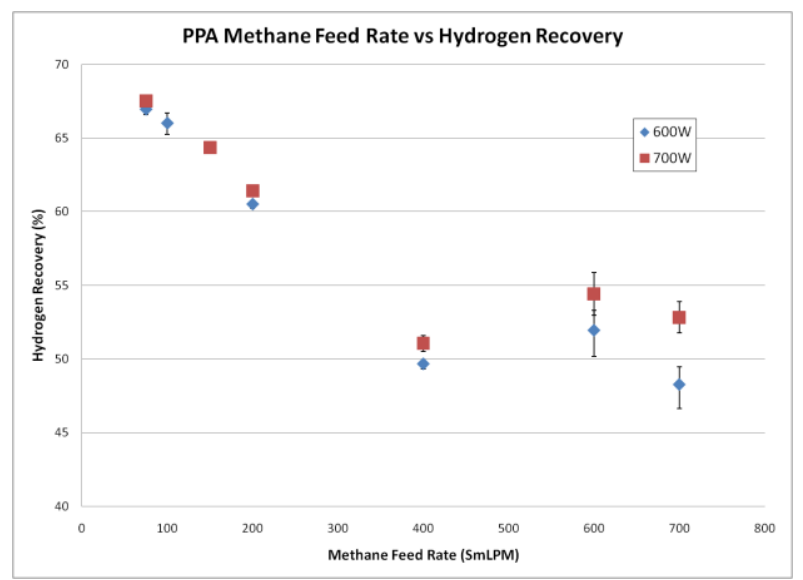

Figure 5. PPA Stand-Alone Hydrogen Recovery. Hydrogen recovery as a function of methane feed rate and microwave power. Error bars indicate standard deviation $(n=3)$.

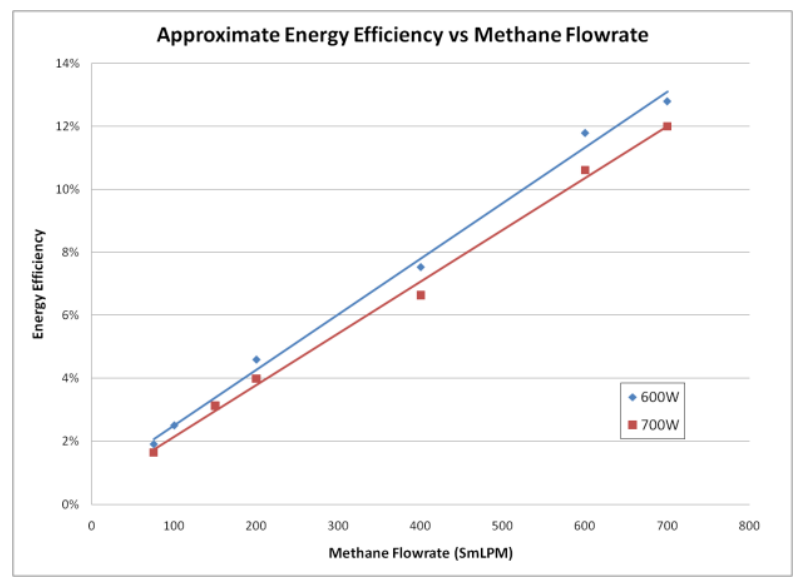

Figure 6. PPA Energy Efficiency. $P P A$ energy efficiency as a function of methane flow rate and microwave power. 


\section{B. SDU Stand-Alone Testing}

SDU Stand-Alone Testing was completed to evaluate the performance of the Sabatier reactor in $\mathrm{H}_{2}$ rich conditions. More specifically, the test was completed to investigate the effect of $\mathrm{H}_{2}: \mathrm{CO}_{2} \mathrm{SDU}$ feed ratios on the methane product stream with respect to $\mathrm{H}_{2}$, methane, and $\mathrm{CO}_{2}$ composition. For this purpose, the system was run with $\mathrm{CO}_{2}$ feed rates equivalent to that of 2 crew at $\mathrm{H}_{2}: \mathrm{CO}_{2}$ ratios of 3.5-6 and 4 crew at $\mathrm{H}_{2}: \mathrm{CO}_{2}$ ratios of 3-6. Due to the $4: 1$ stoichiometric ratio of $\mathrm{H}_{2}$ to $\mathrm{CO}_{2}$ for the Sabatier reaction, the presence of $\mathrm{CO}_{2}$ with minimal or no $\mathrm{H}_{2}$ was expected for SDU ratios <4. Similarly, minimal $\mathrm{CO}_{2}$ and the presence of $\mathrm{H}_{2}$ was expected for SDU ratios >4. Hydrogen concentration, $\mathrm{CO}_{2}$ concentration (mole \%) and methane concentration (mole \%) in the methane product stream are shown in Figure 7-9, respectively. The data in these figures agreed with the expected performance of the SDU. Methane composition varied from $\sim 30 \%$ at the $6: 1$ ratio up to $\sim 85 \%$ at the $3.5: 1$ ratio. For all components, the SDU product stream did not vary significantly with the number of crew $\left(\mathrm{CO}_{2}\right.$ feed rate) indicating consistent reaction performance from the reactor. The data gathered in the SDU Stand-Alone Testing is significant in that it provides the necessary information for SDU/PPA Integrated Testing. The product stream of the SDU provided reliable and predictable products that can be easily manipulated for Integrated Testing by simply changing the $\mathrm{H}_{2}: \mathrm{CO}_{2}$ feed ratio to the SDU. Additionally, no $\mathrm{CO}_{2}$ was observed in the methane product stream at ratios of 4.5 and greater. This provided a starting point for the integrated testing to ensure the absence of oxygenated compounds fed to the PPA. Finally, the Stand-Alone Testing provided baseline SDU performance data to compare with integrated SDU performance data.

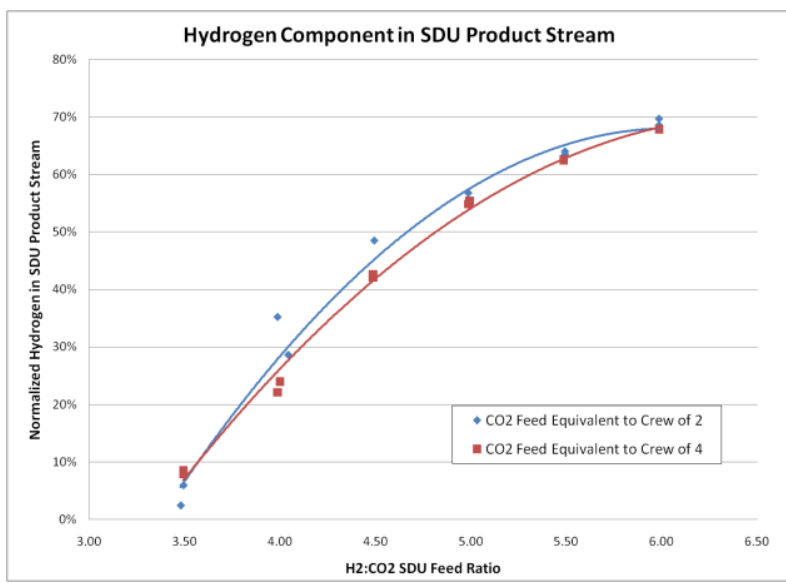

Figure 7. Hydrogen in SDU Methane Stream. Hydrogen shown as a mole \% of the total SDU methane product stream (excluding residual water).

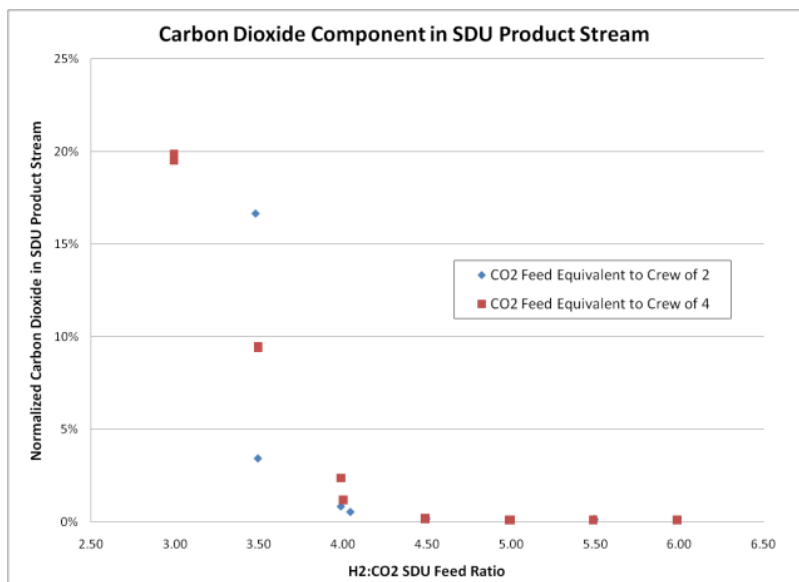

Figure 8. Carbon Dioxide in SDU Methane Stream. CO2 shown as a mole \% of the total SDU methane product stream (excluding residual water).

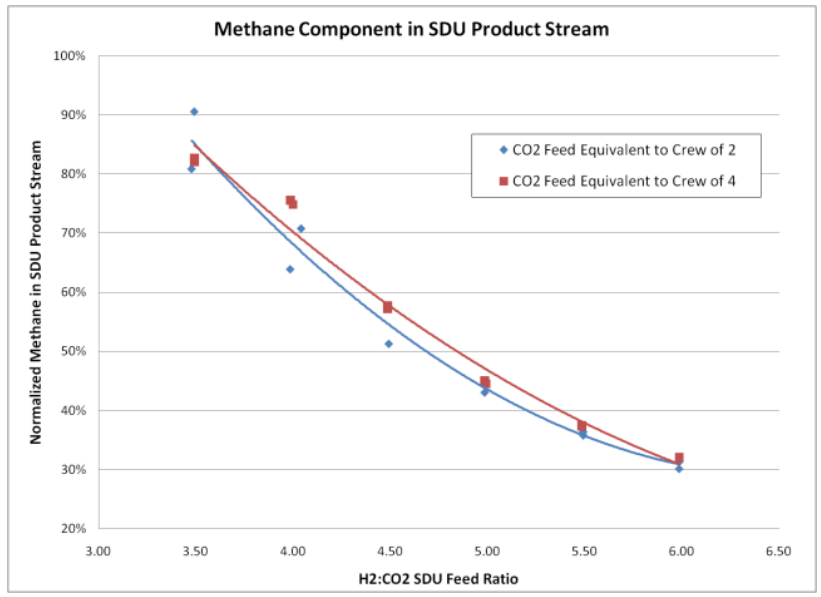

Figure 9. Methane in SDU Methane Stream. Methane shown as a mole \% of the total SDU methane product stream (excluding residual water). 


\section{SDU/PPA Integrated Testing}

SDU/PPA Integrated Testing was completed to evaluate the performance of the SDU and the PPA in an integrated configuration. The observed Integrated Testing performance includes the results of SDU Performance Comparison among three tests, and the three methods as described below. Minitab Statistical Software 15 (Minitab, Inc., State College, PA) and Microsoft Excel were used to evaluate the data for all integrated testing.

\section{SDU Performance Comparison Results}

The SDU Performance Comparison was completed to ensure consistent performance of the SDU during all runs. SDU product stream data was collected during each of Method 1-3 and combined to compare to SDU Stand-Alone data. Individual data points for percent methane in the SDU product stream (excluding water) from each trial are shown in Figure 10. Although there is some variation in the data, the difference in points is not significant $(\alpha \geq 0.05)$ for each SDU ratio. This can be seen more clearly in Figure 11, where both percent $\mathrm{H}_{2}$ and percent methane are shown. Error bars indicate a single standard deviation.

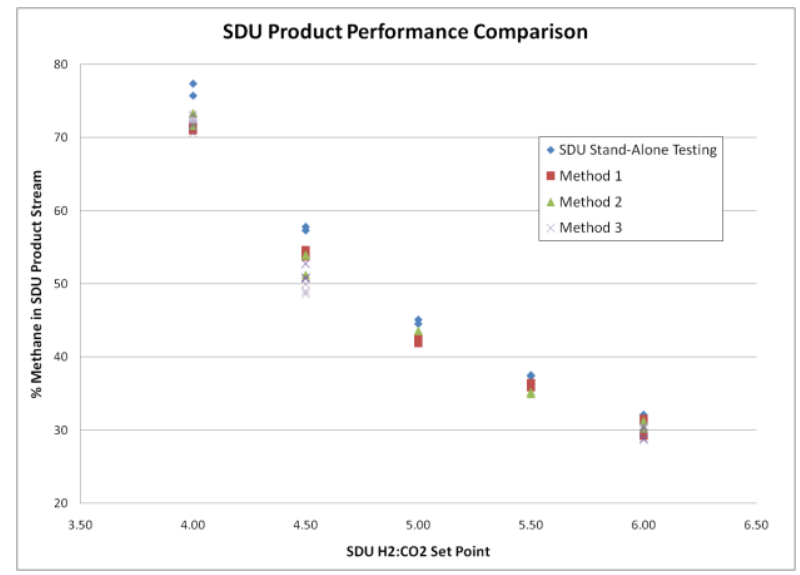

Figure 10. SDU Product Performance Comparison. Methane mole \% in the SDU methane product stream is shown for SDU Stand-Alone Testing and the three methods of Integrated Testing.

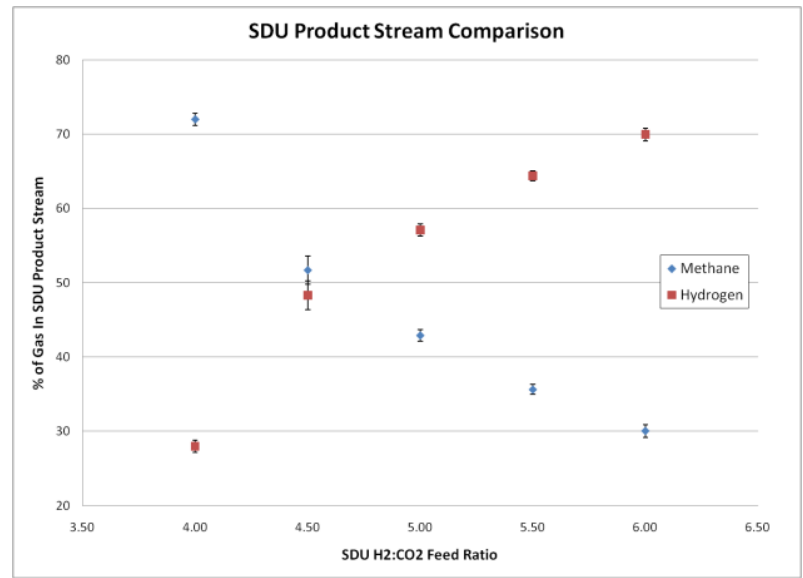

Figure 11. SDU Product Stream Comparison. Average methane and hydrogen mole \% are shown for multiple feed ratios. Error bars indicate a single standard deviation.

\section{SDU/PPA Integrated Testing: Method 1Results}

Method 1 was completed to determine the effect of total system $\mathrm{H}_{2}$ on the methane conversion and pyrolysis products. A regression of methane conversion versus percent system $\mathrm{H}_{2}$ was completed for linear, quadratic and cubic fits. A linear fit was shown to be significant $(\alpha \leq 0.05)$ as shown in Figure 12, suggesting that excess $\mathrm{H}_{2}$ in the PPA would result in lower conversion of methane. Similarly, a regression of methane conversion versus percent $\mathrm{H}_{2}$ in the methane feed was completed for each fit type. A quadratic fit was shown to be significant as shown in Figure 13. However, because $\% \mathrm{H}_{2}$ in the methane feed is directly proportional to total $\mathrm{H}_{2}$ in the system for Method 1, the two parameters are convoluted in this set of testing. Additionally, external $\mathrm{H}_{2}$ was fed to the system at a constant ratio between ports (56\% to the main port, 35\% to the window sweep port, and $9 \%$ to the view sweep port). Additional testing (Methods 2 and 3) was required to determine if this relationship was related to the $\mathrm{H}_{2}$ in the feed, the total system $\mathrm{H}_{2}$, or the distribution of external $\mathrm{H}_{2}$ to each of the ports, as well as to determine if this observed trend translated to a wider range of total system $\mathrm{H}_{2}$. The effect of $\mathrm{H}_{2}$ in the system on the selectivity of acetylene (versus other hydrocarbon products) was also investigated. However, the fit was inadequate to conclusively say there was a relationship between the two. Additional testing (Method 3) was necessary to further evaluate the factors affecting the selectivity of acetylene and methane conversion. 


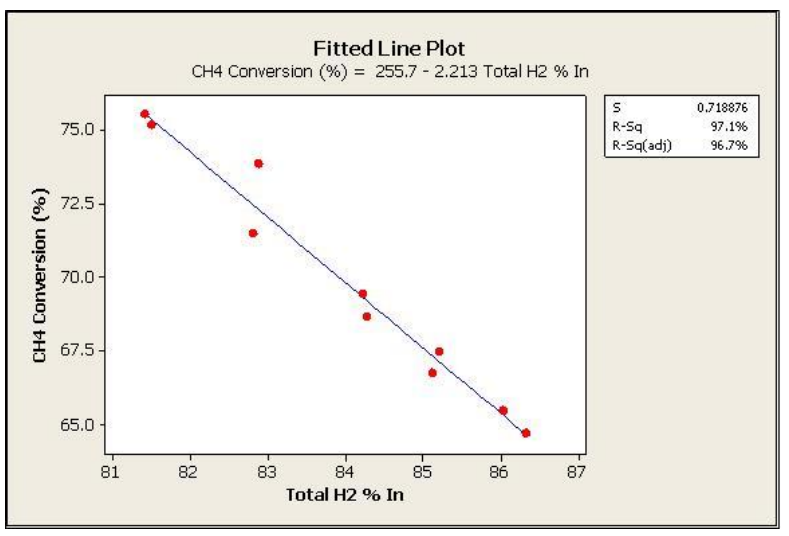

Figure 12. Methane Conversion vs Total System Hydrogen. A linear fit indicates a correlation between methane conversion and the total system hydrogen for Method 1 testing.

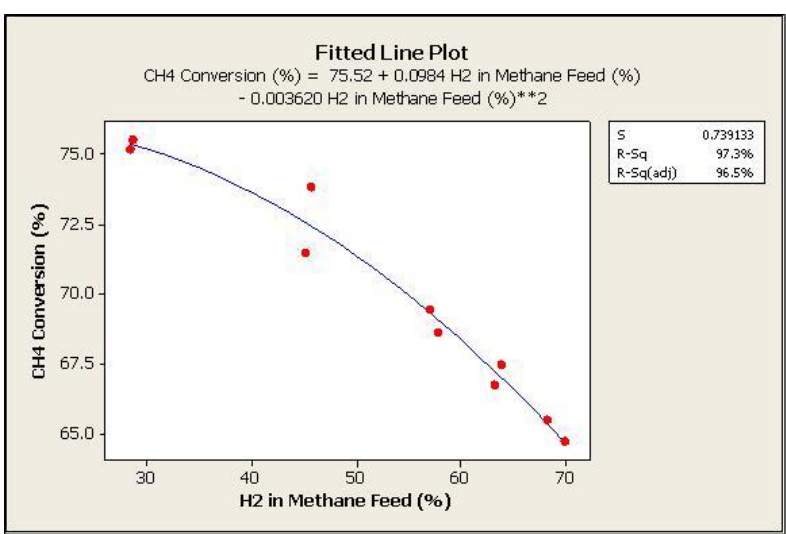

Figure 13. Methane Conversion vs Hydrogen in the Methane Feed Stream - Method 1. A quadratic fit indicates a correlation between methane conversion and the mole \% of hydrogen in the methane feed stream for Method 1 testing.

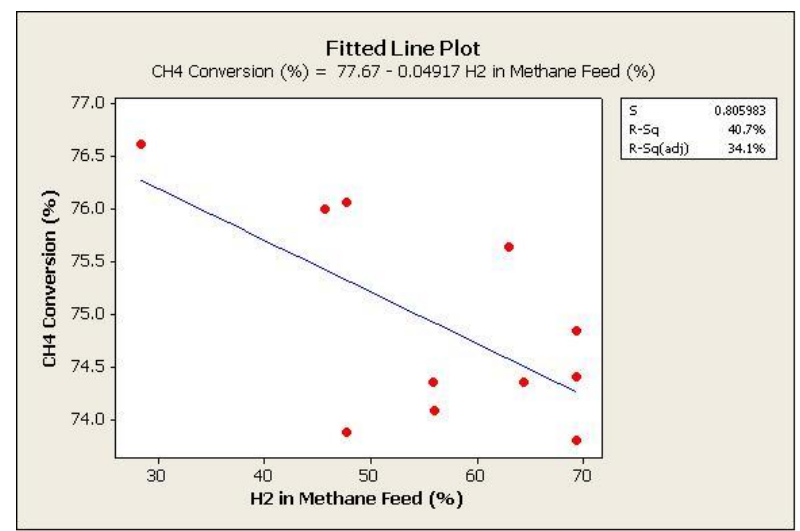

Figure 14. Methane Conversion vs Hydrogen in Methane Feed Stream - Method 2. No correlation was observed between methane conversion and the mole \% of hydrogen in the methane stream for Method 2 testing.

\section{SDU/PPA Integrated Testing: Method 2 Results}

Method 2 testing was completed to determine the effect of varying the source of $\mathrm{H}_{2}$ while keeping the total system $\mathrm{H}_{2}$ constant. More specifically, testing was completed to determine if the correlation between methane conversion and total system $\mathrm{H}_{2}$ was due to total system $\mathrm{H}_{2}$, or due to the percent $\mathrm{H}_{2}$ in the methane feed stream. Note that for Method 2, both the total system $\mathrm{H}_{2}$ and the ratio between ports of the external $\mathrm{H}_{2}$ were kept constant. As seen in Figure 14, there was no correlation between methane conversion and percent $\mathrm{H}_{2}$ in the feed stream. Due to the limited variation in total system $\mathrm{H}_{2}$, an absolute conclusion could not yet be determined regarding the effect of total system $\mathrm{H}_{2}$ on methane conversion or $\mathrm{H}_{2}$ recovery. However, the data suggest that the total system $\mathrm{H}_{2}$ was the deciding factor in determining methane conversion. Method 3 provides significantly more breadth with regards to percent $\mathrm{H}_{2}$ at each inlet point.

\section{SDU/PPA Integrated Testing: Method 3 Results}

Method 3 was completed to conclusively determine if total system $\mathrm{H}_{2}$ or percent $\mathrm{H}_{2}$ in methane feed were factors in the percent conversion of methane. Additionally, because both Method 1 and Method 2 were run with a constant $\mathrm{H}_{2}$ distribution between the three external $\mathrm{H}_{2}$ ports $(56 \%$ to main port, $35 \%$ to window sweep port, and $9 \%$ to view sweep port), Method 3 sought to explore the effect of varying this distribution.

No clear relationship was observed between total system $\mathrm{H}_{2}$ and percent conversion of methane. However, a quadratic relationship was observed for percent $\mathrm{H}_{2}$ in methane feed and methane conversion, as seen in Figure 15.

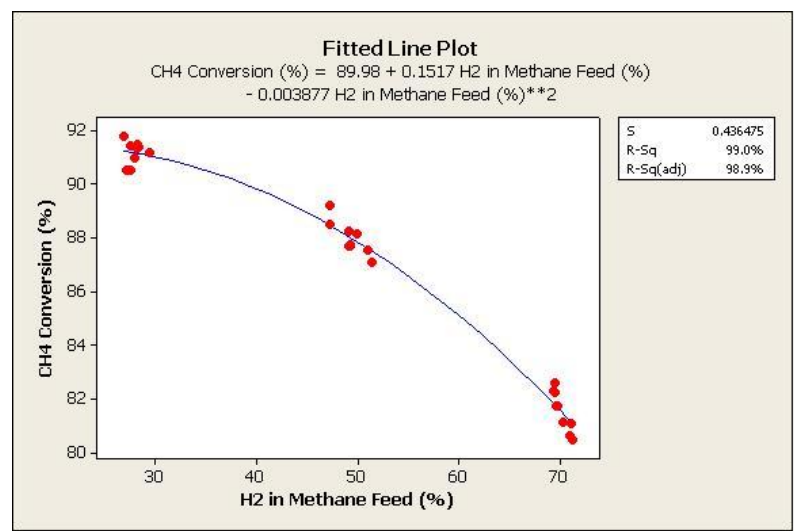

Figure 15. Methane Conversion vs Hydrogen in Methane Feed Stream - Method 3. A quadratic correlation was observed between methane conversion and the mole \% of hydrogen in the methane stream for Method 3 testing. 
The lack of a relationship between the total system $\mathrm{H}_{2}$ and methane conversion is consistent with data from Method 1 and Method 2, indicating that the total system $\mathrm{H}_{2}$ cannot be directly and solely related to the methane conversion in the PPA. However, the data in Figure 15 matches what was observed in Method 1(Figure 13), but contradicts the data in Method 2(Figure 14) where the data indicated no relationship between $\mathrm{H}_{2}$ in the methane feed and methane conversion. Clearly, a more thorough analysis was required to fully understand these relationships. For this purpose, a fully quadratic Response Surface Analysis (RSA) was completed on the combined data from the three methods. The factors in the analysis included the quantity of $\mathrm{H}_{2}$ entering the PPA from each feed port (methane feed port, main port, window sweep port, and view sweep port). Methane conversion, $\mathrm{H}_{2}$ recovery and percent carbon recovered as acetylene were investigated as responses. As suggested in the basic analyses of Methods 1,2 and 3, the interactions between system $\mathrm{H}_{2}$ and each response was highly complicated. In fact, not only was the $\mathrm{H}_{2}$ from each port significant in predicting methane conversion, $\mathrm{H}_{2}$ recovery, and percent carbon recovered as acetylene, so were the interactions between many of the ports $(\alpha<<0.05)$.

Based on the analysis and the data available, an optimization analysis was completed for significant factors. This analysis allowed the software to search for optimum values to meet certain requirements. The goal was to maximize methane conversion, maximize $\mathrm{H}_{2}$ recovery, and maximize percent carbon as acetylene. The analysis allowed for no extrapolation outside of factor ranges, but depended on interpolation within the gathered data. The optimization profile is shown in Figure 16. The top of the figure shows the streams of interest $\left(\mathrm{H}_{2}\right.$ in methane feed, $\mathrm{H}_{2}$ in main port, $\mathrm{H}_{2}$ in view sweep port, and $\mathrm{H}_{2}$ in window sweep port). Below the names of each feed port, the observed high and low values are shown. The center value, in red, indicates the optimum set-point as determined by the analysis to meet the requirements. On the left side of the graph, a composite desirability is calculated indicating the level to which the requirements were met. Also on the left side are the responses to be optimized (methane conversion, hydrogen recovery, and percent carbon as acetylene) and their specific desirabilities. The graphs show the curves associated with each combination of factors. From this figure, it can be seen that minimum values of $\mathrm{H}_{2}$ in the main port

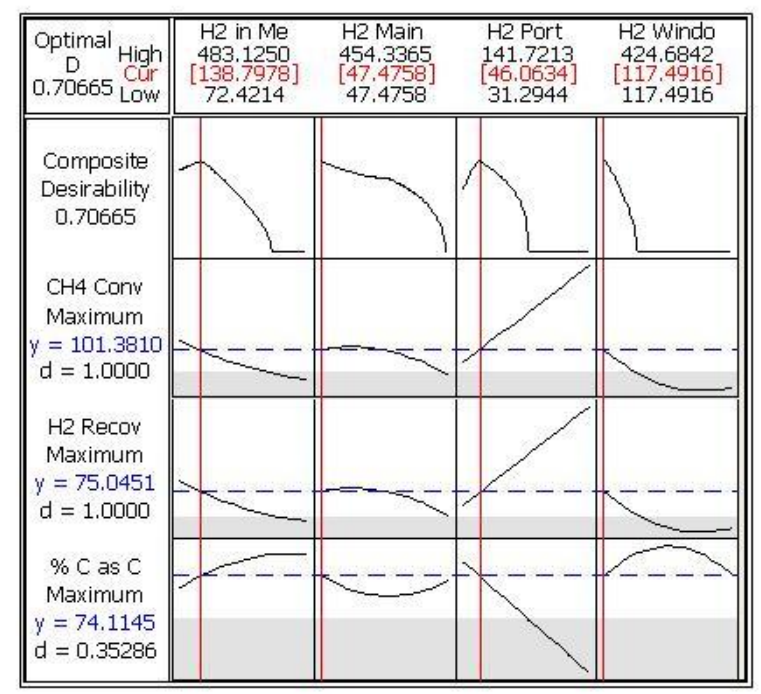

Figure 16. PPA System Hydrogen Feed Optimization. Minitab Statistical Software was used to search for factor levels aimed at maximizing methane conversion, hydrogen recovery, and \% carbon as acetylene.

and window sweep port are best.

Additionally, low values for $\mathrm{H}_{2}$ in the methane feed and the view sweep port are also best. This data now correlates to the analysis completed for Method 1 that suggested lower system $\mathrm{H}_{2}$ was best for methane conversion. Additionally, not just the $\mathrm{H}_{2}$ in the methane feed port, but $\mathrm{H}_{2}$ entering the system from all ports, affect methane conversion, $\mathrm{H}_{2}$ recovery, and the resulting hydrocarbon products. It should be noted that while decreasing system $\mathrm{H}_{2}$ would result in improved methane conversion, this would also increase the formation of solid carbon and other carbonaceous products in the system. A delicate balance must be maintained to ensure the best developed product. A summary of findings is shown in Table 2.

\section{Conclusion}

Testing was completed to evaluate the stand-alone and integrated performance of the SDU and PPA. Stand-alone performance of the PPA showed methane conversion and $\mathrm{H}_{2}$ recovery to be dependent on microwave power (degree of ionization) and methane feed rates (residence time). Stand-alone performance of the SDU showed minimal carbon dioxide in the methane product stream at $\mathrm{H}_{2}: \mathrm{CO}_{2}$ ratios 4.5 and higher. Data taken through multiple tests indicated minimal variation in the SDU product stream at given SDU feed ratios. Finally, integrated testing indicated a very complex system with regards to hydrogen feed control and methane conversion. Due to the information obtained in this testing, it is clear that careful thought will be required for future development and upscaling of the PPA. Finally, it should be noted that testing discussed in this document involved no oxygenated 
compounds entering the PPA. Future work must include an investigation into the effects of water and $\mathrm{CO}_{2}$ in the methane feed on PPA products. Additionally, future testing should include an evaluation of the effect of methane in sweep ports, potentially reducing the quantity of external $\mathrm{H}_{2}$ necessary for a "clean" reactor, and an advanced study of the production of hydrocarbons other than acetylene.

Table 2. Key Findings of Testing. A summary of key findings of PPA Stand-Alone Testing, SDU Stand-Alone Testing, and SDU/PPA Integrated Testing.

\begin{tabular}{|c|c|}
\hline Test & Key Findings \\
\hline \multirow{3}{*}{ PPA Stand-Alone Testing } & $\begin{array}{l}700 \mathrm{~W} \text { microwave power results in improved methane conversion over } 600 \mathrm{~W} \\
\text { for most methane flow rates }\end{array}$ \\
\hline & $\begin{array}{l}\text { Methane flow rates } \geq 400 \text { SmLPM show decreased methane conversion and } \\
\text { hydrogen recovery compared to methane flow rates } \leq 200 \text { SmLPM }\end{array}$ \\
\hline & High methane flow rates result in improved energy efficiency of the PPA \\
\hline \multirow[b]{2}{*}{ SDU Stand-Alone Testing } & The SDU reduces $\mathrm{CO}_{2}$ at similar efficiency for feeds equal to 2 or 4 crew \\
\hline & $\begin{array}{l}\text { The SDU provides nearly } 100 \% \text { conversion of } \mathrm{CO}_{2} \text { at } \mathrm{H}_{2}: \mathrm{CO}_{2} \text { ratios of } 4.5 \\
\text { and greater }\end{array}$ \\
\hline SDU Performance Comparis on & The SDU performance was consistent over multiple days, trials, tests, etc. \\
\hline SDU/PPA Integrated: Method 1 & Suggests that hydrogen in the system reduces methane conversion \\
\hline SDU/PPA Integrated: Method 2 & $\begin{array}{l}\text { Methane conversion was not solely related to hydrogen in the methane feed } \\
\text { stream }\end{array}$ \\
\hline \multirow{2}{*}{ SDU/PPA Integrated: Method 3} & $\begin{array}{l}\text { Methane conversion, hydrogen recovery and \%C as acetylene are complex } \\
\text { and related to independent feeds of hydrogen to the system, including that } \\
\text { in the methane feed stream }\end{array}$ \\
\hline & $\begin{array}{l}\text { Optimization indicates that minimizing hydrogen in the external hydrogen } \\
\text { ports would improve methane conversion, hydrogen recovery, and \% C as } \\
\text { acetylene }\end{array}$ \\
\hline
\end{tabular}

\section{Acknowledgments}

The authors would like to acknowledge UMPQUA Research Company and Hamilton Sundstrand for their continued assistance with system hardware. They would like to acknowledge the Environmental Gas Laboratory group at MSFC for sample analysis, Curtis Leslie and Kenny Bodkin for testing support, and Joseph Scott for laboratory support.

\section{References}

${ }^{1}$ Murdoch, K.,J., Perry, J., Smith, F., "Sabatier Engineering Development Unit," 33rd International Conference on Environmental Systems, SAE International, Vancouver, Canada, 2003.

${ }^{2}$ Knox, J.C., Campbell, M., Murdoch, K., Miller, L.A., Jeng, F, "Integrated Test and Evaluation of a 4-Bed Molecular Sieve(4BMS) Carbon Dioxide Removal System (CDRA), Mechanical Compressor Engineering Development Unit (EDU), and Sabatier Engineering Development Unit (EDU)," 35th International Conference on Environmental Systems, SAE International, Rome, Italy, 2005.

${ }^{3}$ Knox, J.C., Miller, L.A., Luna, B., Campbell, M., "Integrated Test and Evaluation of a 4-Bed Molecular Sieve (4BMS) Carbon Dioxide Removal System (CDRA), Temperature Swing Adsorption Compressor (TSAC), and Sabatier Engineering Development Unit (EDU)," 36th International Conference on Environmental Systems, SAE International, Norfolk, Virginia, 2006.

${ }^{4}$ Atwater, J. E., Wheeler, R. R., Jr., Hadley, N. M., Dahl, R. W., Carrasquillo, R. L., "Development and Testing of a Prototype Microwave Plasma Reactor for Hydrogen Recovery from Sabatier Waste Methane," 39th International Conference on Environmental Systems, SAE International, Savannah, Georgia, 2009.

${ }^{5}$ Schunk, R.G., Bagdigian, R.M., Carrasquillo, R.L., Ogle, K.Y., Wieland, P.O., "Space Station ECLSS Simplified Integrated Test Final Report," NASA Technical Memorandum, 100363, 1989.

${ }^{6}$ Fridman, A., "Plasma Chemistry," Cambridge University Press, New York, New York, 2008. 